Dez 2020 a Fev 2021 - v.14 - n.1

\title{
Ação antimicrobiana de actinomicetos rizosféricos de guaranazeiro
}

Conhecido popularmente como guaraná, Paullinia cupana Kunth var. sorbilis (Mart.) Ducke, da tribo Paullinieae, família Sapindaceae, é uma espécie nativa brasileira de considerável importância econômica na indústria farmacêutica e de alimentos. Os actinomicetos são qualitativa e quantitativamente importantes na rizosfera, podendo influenciar o crescimento de plantas e proteger as raízes da invasão de fungos patogênicos, podendo desta maneira, serem utilizados no controle biológico de doenças em plantações. Este trabalho teve como objetivo avaliar ação antibacteriana de actinomicetos rizosféricos de guaranazeiro de plantações localizadas no município de Maués/AM, com o intuito de encontrar novos agentes antimicrobianos frente a bactérias patogênicas aos seres humanos. Foram investigados 17 actinomicetos isolados da rizosfera de guaranazeiro, e avaliados quanto sua atividade antimicrobiana frente a quatro bactérias patogênicas de interesse clínico. Staphylococcus aureus, Streptococcus pneumococo, Enterococcus faecalis e Bacilus subtilis. A avaliação da atividade antagônica pelos isolados, foi realizada através do método de cross streak e termoestabilidade. Os resultados revelaram que o isolado ACT 4 possibilitou a inibição de apenas dois patógenos, sendo estes, Staphylococcus aureus e Bacillus subtilis, enquanto o isolado ACT 93 exibiu amplo espectro de atividade contra todas as bactérias patogênicas grampositivas avaliadas. Quanto à termoestabilidade e produção de metabólitos pelos isolados, apenas o isolado ACT 4 conseguiu inibir uma bactéria Enterococcus faecalis. Este estudo mostra que os isolados de actinomicetos têm o potencial de atuar como possíveis fontes de novos compostos antibacteriano contra microorganismos patogênicos humanos. No entanto, ensaios mais aprofundados são necessários para que futuramente possam se formar uma entrada importante na indústria farmacêutica.

Palavras-chave: Actinomicetos; Bioativos; Guaranazeiro; Bactérias patogênicas.

\section{Antimicrobial action of guaranazeiro rizospheric actinomycetes}

Popularly known as guarana, Paullinia cupana Kunth var. sorbilis (Mart.) Ducke, from the Paullinieae tribe, Sapindaceae family, is a native Brazilian species of considerable economic importance in the pharmaceutical and food industry. Actinomycetes are qualitatively and quantitatively important in the rhizosphere, being able to influence plant growth and protect the roots from the invasion of pathogenic fungi, thus being able to be used in the biological control of diseases in plantations. This work aimed to evaluate the antibacterial action of rhizospheric actinomycetes from guaranazeiro from plantations located in the municipality of Maués/AM, in order to find new antimicrobial agents against pathogenic bacteria in humans. 17 actinomycetes isolated from the guaranazeiro rhizosphere were investigated and evaluated for their antimicrobial activity against four pathogenic bacteria of clinical interest. Staphylococcus aureus, Streptococcus pneumococcus, Enterococcus faecalis and Bacilus subtilis. The evaluation of antagonistic activity by the isolates was performed using the cross streak and thermostability method. The results revealed that the ACT 4 isolate enabled the inhibition of only two pathogens, Staphylococcus aureus and Bacillus subtilis, while the ACT 93 isolate exhibited a broad spectrum of activity against all the gram-positive pathogenic bacteria evaluated. As for thermostability and production of metabolites by the isolates, only the ACT 4 isolate was able to inhibit an Enterococcus faecalis bacterium. This study shows that actinomycete isolates have the potential to act as potential sources of new antibacterial compounds against human pathogenic microorganisms. However, more in-depth testing is needed so that an important entry into the pharmaceutical industry can take place in the future.

Keywords: Actinomycetes; Bioactive; Guaranazeiro; Pathogenic bacteria.

Topic: Microbiologia

Reviewed anonymously in the process of blind peer.
Received: 05/12/2020

Approved: 20/02/2021
Suzana da Silva de Oliveira Martins

Universidade do Estado do Amazonas, Brasil

http://lattes.cnpq.br/8483413799152587

http://orcid.org/0000-0001-7041-328X

stay suzy@yahoo.com.br

José Luiz Vargas de Mendonça (ii)

University of Michigan, Estados Unidos

http://lattes.cnpq.br/4939980150228138

http://orcid.org/0000-0002-5931-9687

jlvm.ind@hotmail.com

Aryana Pinheiro do Nascimento

Universidade Federal do Amazonas, Brasil

http://lattes.cnpq.br/6237149794513205 aryana.bio@gmail.com

\section{Pedro de Queiroz Costa Neto (1D) \\ Universidade Federal do Amazonas, Brasi http://lattes.cnpq.br/9441888603413825 \\ http://orcid.org/0000-0002-1907-7492 \\ enaneto16@yahoo.com.br}

Andrezza Miná Barbosa (id

Universidade Federal da Paraíba, Brasil

http://lattes.cnpq.br/6259554827138034

http://orcid.org/0000-0001-5575-5724

andrezzamina@yahoo.com.br

\section{Referencing this:}

MARTINS, S. S. O.; MENDONÇA, J. L. V.; NASCIMENTO, A. P.; COSTA NETO, P. Q.; BARBOSA, A. M.. Ação antimicrobiana de actinomicetos rizosféricos de guaranazeiro. Nature and Conservation, v.14, n.1 p.83-89, 2021. DOI: http://doi.org/10.6008/CBPC23182881.2021.001.0009 


\section{INTRODUÇÃO}

A indústria farmacêutica tem buscado novos medicamentos que possam reduzir efeitos colaterais indesejáveis, o que justifica a busca por novos medicamentos. Sendo assim, a obtenção de produtos oriundos de micro-organismos leva uma vantagem em relação às substâncias químicas por serem compostos termoestáveis, específicos e apresentarem estabilidade de pH (COSTELLOE et al., 2010). Como pode ser observada, a literatura está repleta de exemplos que indicam a potencialidade da utilização de microorganismos na produção de compostos de importância comercial e dentre estes micro-organismos, grande parte dessa produção é dada aos actinomicetos. Estas características os tornam promissores, estimulando ainda mais a busca de novos micro-organismos produtores de compostos bioativos, principalmente na região Amazônica devido à grande diversidade de plantas e nichos exóticos que ainda não foram estudados. Dessa forma, a chance de encontrar novos fármacos, como por exemplo, novas substâncias antimicrobianas, são grandes.

Existem muitas empresas e países interessados nessa potencialidade, entretanto, inversamente proporcional é o investimento em pesquisas aqui no Brasil em relação a essa biodiversidade. Pouco se conhece das espécies de plantas, insetos, animais, e menos ainda ao que se refere aos micro-organismos.

Recentemente um grupo de pesquisadores americanos liderados por Smith et al. (2008) identificaram na Amazônia ocidental, várias espécies novas de actinomicetos. Isto ressalta a importância da necessidade de que mais estudos sejam realizados por pesquisadores brasileiros, pois além de promover a conservação da biodiversidade existente na região amazônica, existe a chance de se encontrar novos microorganismos com vasto potencial biotecnológico. Cabe a nós proteger e utilizar em nosso benefício essa potencialidade microbiana existente na região amazônica.

Os micro-organismos apresentam uma grande vantagem para a produção de compostos de interesse comercial devido ao fato de serem cultivados em grandes escalas e seus compostos facilmente purificados. Embora na literatura já se tenha conhecido resultados realmente admiráveis envolvendo os actinomicetos, estes relatos não esgotam nem de longe frente aos benefícios científicos que estão por ser descobertos. É evidente que, no Brasil, um número maior de pesquisadores deve ser formado, não só para estudar as espécies já conhecidas, como também toda a biodiversidade ainda inexplorada, principalmente nas regiões de clima tropical como a Amazônia.

Deste modo, fica evidente a importância de um esforço concentrado na busca de actinomicetos tanto endofíticos como de solo de valor biotecnológico, econômico e acadêmico. Com essa grande diversidade encontrada na região amazônica, resultados expressivos poderão ser obtidos com micro-organismos, principalmente os actinomicetos. As perspectivas abertas para o estudo desta microbiota são imensas, no que se refere aos estudos biotecnológicos, tanto a nível molecular descobrindo novos genes ligados ao controle biológico de pragas e doenças, produção de enzimas, produtos aromáticos, corantes, biorremediação de compostos tóxicos como também a produção de metabólitos secundários de atividades terapêuticas. 
Outro ponto a ser levado em consideração é que ainda é pequeno o número de pesquisas envolvendo estes micro-organismos em plantas tropicais, onde o potencial biotecnológico deve se concentrar.

Em um ambiente competitivo de mercado, as atividades de bioprospecção são de grande valia e certamente, em pouco tempo, resultados de valor aplicado estarão disponíveis permitindo o uso da biodiversidade microbiana nos mais diversos segmentos. Existem muitas empresas e países interessados nessa potencialidade, cabendo a nós proteger e utilizar em nosso benefício a biodiversidade microbiana existente em regiões tropicais e subtropicais.

Conhecido popularmente como guaraná, Paullinia cupana Kunth var. sorbilis (Mart.) Ducke, planta com hábito trepador da tribo Paullinieae, família Sapindaceae, que possui um alto valor econômico para o Brasil, na indústria farmacêutica e de alimentos. Os actinomicetos são qualitativa e quantitativamente importantes na rizosfera (LECHEVALIER, 1994), podendo influenciar o crescimento de plantas e proteger as raízes da invasão de fungos patogênicos, podendo desta maneira, serem utilizados no controle biológico de doenças em plantações (CRAWFORD, 1993).

A busca de novos agentes antimicrobianos vem sendo ponto crucial de vários setores do campo farmacêutico. Estudo dessa natureza é o ponto de partida para a descoberta da atividade farmacológica de novos agentes, análises extremamente importantes, principalmente em um país como o Brasil com toda a sua grande biodiversidade (TEIXEIRA et al., 2013). A realização deste trabalho teve como objetivo avaliar ação antibacteriano de actinomicetos rizosféricos de guaranazeiro, considerando a possibilidade de obter compostos bioativos de novos agentes antimicrobianos frente a bactérias patogênicas a humanos.

\section{MATERIAIS E MÉTODOS}

O trabalho foi realizado no Laboratório de Princípios Bioativos de Origem Microbiana-LPBOM da Faculdade de Ciências Agrárias situada na Universidade Federal do Amazonas - UFAM, setor Sul, Manaus.

Os actinomicetos coletados fazem parte da Coleção de micro-organismos do LPBOM, que foram isolados da rizosfera de guaranazeiro de plantações localizadas no município de Maués/AM (Figura 1)

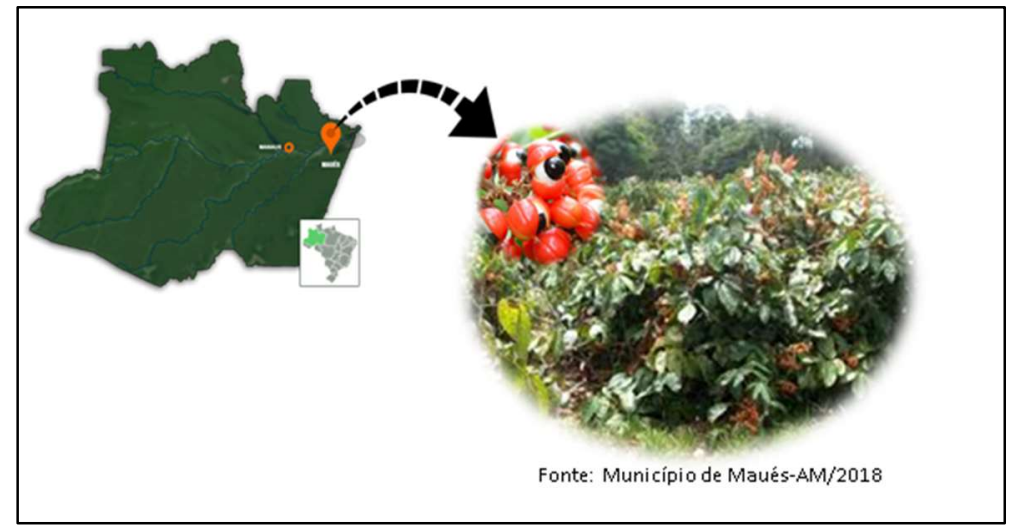

Figura 1: Isolamento dos actinomicetos de culturas do guaraná no Município de Maués-AM.

\section{Reativação dos actinomicetos}

Os actinomicetes foram reativados em meio ágar amido caseína (ACA - amido 1\%, caseína 0,03\%, 
$\mathrm{KNO}_{3} 0,2 \%, \mathrm{NaCl} 0,2 \%, \mathrm{~K}_{2} \mathrm{HPO}_{4} 0,2 \%, \mathrm{MgSO}_{4} 0,0005 \%, \mathrm{FeSO}_{4} 0,001 \%$ e ágar 1,5\%), as placas foram incubadas a $30^{\circ} \mathrm{C}$ durante oito dias, as colônias foram repicadas para testes posteriores (KÜPPER et al., 2009).

\section{Reativação das bactérias patogênicas - cepas padrão}

As cepas padrões Staphylococcus aureus, Enterococcus faecalis, Streptococcus pneumococo, Bacillus subtillis, foram cedidas pela Coleção de Bactérias isoladas de solo do Laboratório de Microbiologia de Alimentos do INPA, sendo reativadas em meio Mueller Hinton, as placas foram incubadas a $30^{\circ} \mathrm{C}$ por $24 \mathrm{~h}$.

\section{Cultura pareada - Método cross streak}

O método cross streak é uma das técnicas importantes usado na triagem preliminar de atividades antimicrobianas para actinomicetos. Esse método determina o potencial de inibição de qualquer microorganismo, produzindo compostos antimicrobianos. Ele tem sido empregado por vários pesquisadores para estudar o potencial antimicrobiano de isolados de actinomicetos (OSKAY et al., 2004; REMYA et al., 2008; DASARI et al., 2011; KEKUDA et al., 2013).

Utilizando-se uma colônia de cada micro-organismo reativado, realizou-se o teste de estrias pareadas também chamado de culturas pareadas, pelo método ágar cross streak, conforme metodologia de Christensen et al. (1996), para verificação do seu potencial antagônico frente aos micro-organismos patogênicos desafiantes por meio de observação de zonas de inibição. Neste ensaio, foi inoculado em meio de cultura ACA os isolados antagonistas de modo diametral em placas de Petri, dois após a inoculação, repicou-se os patógenos no modo horizontal, incubando por $24 \mathrm{~h}$ a $30^{\circ} \mathrm{C}$. O controle negativo consistiu apenas do cultivo dos isolados patogênicos. O delineamento experimental foi inteiramente casualizado com três repetições cada (Figura 2).

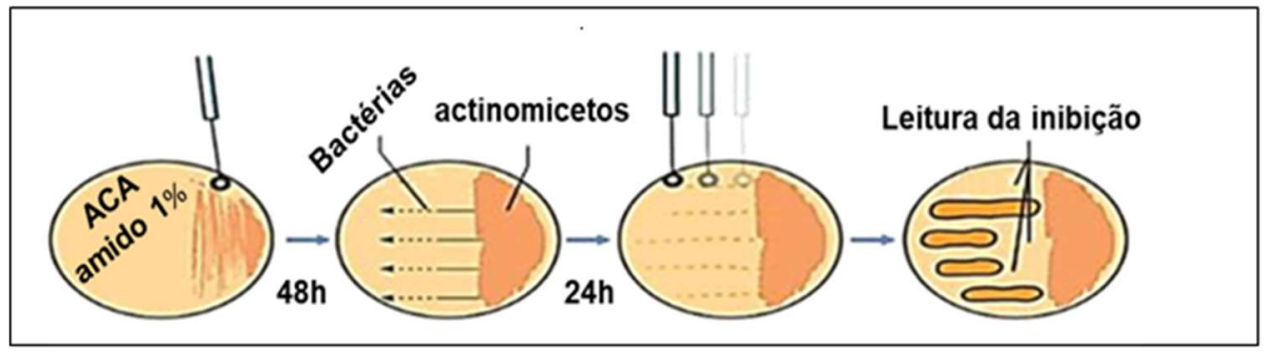

Figura 2: Esquema de cultura pareada pelo método cross streak.

\section{Avaliação da produção e termoestabilidade de metabólitos pelos isolados}

Para testar a produção e termoestabilidade de metabólitos produzidos pelos isolados endofiticos, colônias dos actinomicetos foram transferidos para o erlenmeyers de $250 \mathrm{~mL}$, contendo $100 \mathrm{~mL}$ de meio líquido a base de amido caseína com 7.2 pH. Após a incubação em condições ambiente de laboratório por 7 dias sob agitação (150 rpm) em agitador mecânico, no escuro, amostras de $10 \mathrm{~mL}$ de cada caldo fermentado foram transferidos para erlenmeyers de $250 \mathrm{~mL}$, contendo $90 \mathrm{~mL}$ de ACA e posteriormente esterilizados em autoclave por $15 \mathrm{~min}$, a $120^{\circ} \mathrm{C}$ e 1 atm de pressão.

Após homogeneização da suspensão, procedeu-se a deposição de $20 \mathrm{~mL}$ em placa de Petri. Após a 
solidificação do meio foram feitas estrias das bactérias patogênicas na superfície do meio com $24 \mathrm{~h}$ de cultivo.

As testemunhas foram constituídas de placas contendo as bactérias patogênicas nos meios de cultura, sem a presença dos metabólitos, incubados a $30^{\circ} \mathrm{C}$ por $24 \mathrm{~h}$. Foi utilizado um delineamento inteiramente ao acaso, com três repetições, cada placa de Petri constituída de uma unidade experimental (Figura 3).

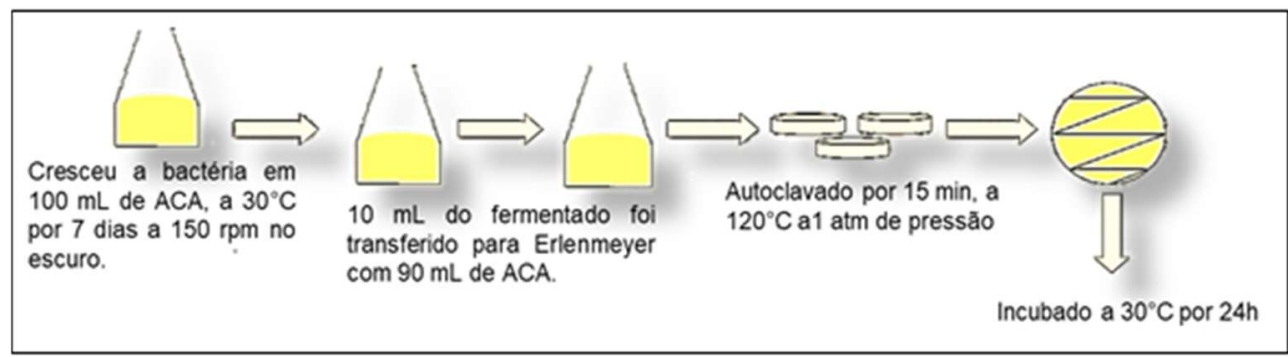

Figura 3: Avaliação da termoestabilidade de metabólitos produzidos pelos actinomicetos.

\section{RESULTADOS E DISCUSSÃO}

Devido ao surgimento de patógenos humanos resistentes a múltiplas drogas, é necessário descobrir novos antibióticos que sejam eficazes contra esses patógenos. Mohseni et al. (2013), para superar este problema, podemos usar o potencial de actinomicetos, que são capazes de produzir compostos bioativos, sendo uma importante fonte de metabólitos secundários (SUTHINDHIRAN et al., 2009).

$\mathrm{Na}$ avaliação da atividade antagônica dos actinomicetos pelo método cross streak. Foram investigados 17 actinomicetos isolados da rizosfera de guaranazeiro, e avaliados quanto sua atividade antimicrobiana frente a quatro bactérias patogênicas de interesse clínico. Desses isolados apenas dois apresentaram atividade antibacteriana contrapelo menos uma das bactérias patogênicas a um nível variado pelo método cross streak. A antibiose foi vista como uma zona clara em torno dos antagonistas inibindo o crescimento dos organismos teste. Os resultados revelaram que o isolado ACT 93 exibiu amplo espectro de atividade contra todas as bactérias patogênicas gram-positivas avaliadas, principalmente contra Enterococcus faecalis e Bacillus subtilis, apresentando inespecificidade de ação, enquanto o isolado ACT 4 possibilitou a inibição de apenas dois patógenos, sendo estes, Bacillus subtilis e Staphylococcus aureus, e considerado dessa forma o menos inibitório (Figura 4).

Apesar do pequeno número amostral de isolados investigados, esses resultados mostram que esses micro-organismos são fontes importantes de metabólitos secundários, e vão de encontro aos resultados já descritos na literatura como o de Mohamed et al. (2017) que isolou 32 actinomicetos do solo do Saara, e 13 mostraram atividade antibacteriana pelo mesmo método acima citado, e os isolados C, MS1 e 10 apresentaram amplo espectro tanto com bactérias gram-positivas quanto com gram-negativas, mais especialmente contra Micrococcus luteus, S. aureus e Staphylococcus epidermidis.

Mesta et al. (2017), avaliaram o potencial antimicrobiano de 43 actinomicetos marinhos isolados de estuários do distrito de UTTARA KANNADA na Índia, e somente os isolados SMRO 13, SMRO 16, SMRO 20, SMRO 27, SMRO 32, SMRO 36 e SMRO 40, demostraram inibição acentuada aos organismos teste, os isolados SMRO 22, SMRO 33, SMRO 34 e SMRO 43, foram os menos inibitórios. E os isolados SMRO 23 e SMRO 42 
foram ineficazes frente a todas as bactérias testadas.

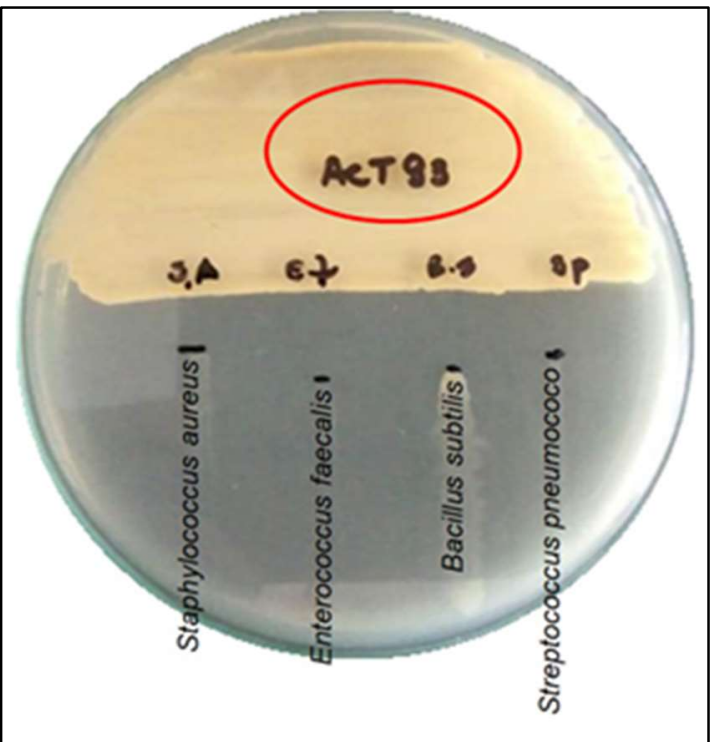

Figura 4: Atividade antagônicas do isolado ACT 93 frente as bactérias patogênicas humanas.

Esses resultados demonstram que apesar desses organismos apresentarem um excelente potencial de produção de metabólitos secundários extracelulares, poucos são os isolados que possuem ação antimicrobiana, e que podem ter atividade antibiótica sendo capazes de inibirem os organismos ora testados.

Uma outra variável a ser discutida neste ensaio, é em relação ao crescimento das estirpes patogênicas, já que foi observado que seu crescimento ocorreu de modo fastidioso, havendo redução de massa bacteriana. A hipótese ora apresentada, é que o meio de cultura ACA, utilizado para o crescimento e posterior produção e excreção de metabólitos secundários pelos actinomicetos, não seja tão nutritivo para promover o melhor desenvolvimento das estirpes patogênicas, mesmo assim, não as incapacitando de crescerem. Na avaliação da produção e termoestabilidade de metabólitos, quanto à termoestabilidade e produção de metabólitos pelos isolados, apenas um isolado, sendo este o ACT 4 conseguiu inibir uma bactéria Enterococcus faecalis.

Na literatura encontram-se pesquisas avaliando termoestabilidade de metabólitos produzidos por bactérias com resultados positivos sobre outros patógenos, no entanto os isolados avaliados neste ensaio, não se mostraram eficientes na inibição de bactérias de interesse clínico, demonstrando que, a molécula que possivelmente atuava no ensaio de cultura pareada pelo método cross streak, possa ter desnaturado durante o processo de autoclavagem e perdido sua capacidade inibitória, possibilitando o crescimento das linhagens patogênicas. Outra hipótese, seria que, o tempo delimitado para o ensaio (7 dias) não foi suficiente para que os actinomicetos produzissem metabólitos suficientes para inibir as bactérias patogênicas avaliadas.

\section{CONCLUSÕES}

As populações de actinomicetos são importantes constituintes da microflora da rizosfera, seja pela capacidade de síntese de antibióticos, permitindo o uso de sua capacidade antagonista no biocontrole de fitopatógenos. Os estudos dos actinomicetos na Amazônia detém cerca de 20\% da biodiversidade mundial, 
principalmente na floresta Amazônica. Entretanto, pouco é conhecido dessa biodiversidade, principalmente dos micro-organismos.

Tornando-se então necessária a conservação dessa biodiversidade ainda desconhecida, que poderá render produtos de grande importância biotecnológica. Pesquisas com actinomicetos isolados da região Amazônica estão sendo feitos, com o objetivo de selecionar novos compostos promissores com potencial biotecnológico.

Este estudo apresentou que os isolados de actinomicetos têm o potencial de atuar como possíveis fontes de novos compostos antibacteriano contra micro-organismos patogênicos humanos. No entanto, ensaios mais aprofundados são necessários para que futuramente possam se formar uma entrada importante na indústria farmacêutica.

\section{REFERÊNCIAS}

CHRISTENSEN, K. D.; JACOBSEN, E. M.; NOHR, H.. A comparative study of bird faunas in conventionally and organically farmed areas. 1996.

COSTELLOE, C.; METCALFE, C.; LOVERING, A.. Effect of antibiotic prescribing in primary care on antimicrobial resistance in individual patients: systematic review and meta-analysis. British Medical Journal, p.1-11, 2010. DOI: https://doi.org/10.1136/bmj.c2096

CRAWFORD, D.. Isolation and characterization of actinomycete antagonists of a fungal root pathogen. Applied and Environmental Microbiology, Washington, v.59, n.11, p.3899-3905, 1993. DOI:

https://doi.org/10.1128/AEM.59.11.3899-3905.1993

DASARI, V. R. R. K.; NIKKU, M. Y.; DONTHIREDDY, S. R. R.. Screening of Antagonistic Marine Actinomycetes: Optimization of Process Parameters for the Production of Novel Antibiotic by Amycolatopsis Alba var. nov. DVR D4. Journal of Microbial and Biochemical Technology, v 3, n.5, p.92-98. 2011. DOI: https://doi.org/10.4172/1948$\underline{5948.1000058}$

KEKUDA, P. T. R.; DILEEP, N.; JUNAID, S.. Biological activities of Streptomyces species SRDP-07 isolated from soil of Thirthahalli, Karnataka, India. International Journal of Drug Development and Research, v.5, n.3, p.268-285, 2013. DOI: https://doi.org/10.7897/2321-6328.01409

KÜPPER, H.; GÖTZ, B.; MIJOVILOVICH, A.. Complexation and toxicity of copper in higher plants. I. Characterization of copper accumulation, speciation, and toxicity in Crassula helmsii as a new copper accumulator. Plant Physiol., v.151, p.702-714, 2009. DOI:

https://doi.org/10.1104/pp.109.139717

LECHEVALIER, H. A.. A pratical guide to generic identification of actinomycetes. In: HOLT, G. H.. Bergeý s. Manual of Determinative bacteriology. 9 ed. Baltimore: Williams \& Wilkins, 1994. p.611-623.

MESTA, S. C.; ONKARAPPA, R.. Characterization and Antimicrobial Potential of Marine Actinomycetes from
Estuaries of Uttara Kannada District, Karnataka. Journal of

Drug \& Therapeutics, v.7, n.6, p.27-37, 2017.

DOI: https://doi.org/10.22270/jddt.v7i6.1527

MOHAMED, H. S.; ALTALHI, A. D.; EL-ZAHRANI, G. S. B.. Isolation and Characterization of Actinobacteria from Algerian Sahara Soils with Antimicrobial Activities. International Journal of Molecular and Cellular Medicine, v.2, n.6, 2017. DOI: https://doi.org/10.22088/ acadpub.BUMS.6.2.5

MOHSENI, M.; NOROUZI, H.; HAMEDI, J.; ROOHI, A.. Screening of antibacterial producing actinomycetes from sediments of the Caspian Sea. Int. J. Mol. Cell. Med., v.2, n.2, p.64-71, 2013. DOI: http://dx.doi.org/10.1590/s2175$\underline{97902019000217249}$

OSKAY, M.; TAMER, U. A.; AZERI, C.. Antibacterial activity of some actinomycetes isolated from farming soils of Turkey. African Journal of Biotechnology, v.3, n.9, p.441-446, 2004. DOI: https://doi.org/10.5897/AJB2004.000-2087

REMYA, M.; VIJAYAKUMAR, R.. Isolation and Characterization of Marine Antagonistic Actinomycetes from West Coast of India. Medicine and Biology, v.15, n.1, p.1319, 2008. DOI: https://doi.org/10.1016/S22211691(12)60078-1

SMITH, S. A.; TANK, D. C.; BOULANGER, L. A.. Bioactive Endophytes Warrant Intensified Exploration and Conservation. Plos One, v.3, p.30-52, 2008. DOI: https://doi.org/10.1371/journal.pone.0003052

SUTHINDHIRAN, K.; KANNABIRAN, K.. Cytotoxic and Antimicrobial Potential of Actinomycete Species Saccharopolyspora salina VITSDK4 Isolated from the Bay of Bengal Coast of India. Am. J. Infect. Dis., v.5, n.2, p.90-98. 2009. DOI: https://doi.org/10.3844 / ajidsp.2009.90.98

TEIXEIRA, M. S.; SILVA, T. A.; PALHETA, R. A.. Fungos da Amazônia: uma riqueza inexplorada. Amazonas: EDUA, 2013.

A CBPC - Companhia Brasileira de Produção Científica (CNPJ: 11.221.422/0001-03) detém os direitos materiais desta publicação. Os direitos referem-se à publicação do trabalho em qualquer parte do mundo, incluindo os direitos às renovações, expansões e disseminações da contribuição, bem como outros direitos subsidiários. Todos os trabalhos publicados eletronicamente poderão posteriormente ser publicados em coletâneas impressas sob coordenação da Sustenere Publishing, da Companhia Brasileira de Produção Científica e seus parceiros autorizados. Os (as) autores (as) preservam os direitos autorais, mas não têm permissão para a publicação da contribuição em outro meio, impresso ou digital, em português ou em tradução. 